\title{
Stimulation by hCG in vivo of oxygen consumption by rabbit oocytes in vitro
}

\author{
C. Magnusson, W. J. LeMaire* and T. Hillensjö \\ Department of Physiology, University of Göteborg, Box 33031, S-400 33 Göteborg, Sweden
}

\begin{abstract}
Summary. Rabbits were injected with 100 i.u. hCG to induce oocyte maturation. Oocytes removed from the ovaries at various times and denuded showed increased oxygen consumption which began before the start of maturation.
\end{abstract}

\section{Introduction}

Meiotic maturation of rat oocytes is accompanied by an increase in oxygen consumption (Magnusson, Hillensjö, Tsafriri, Hultborn \& Ahrén, 1977). This rise in oxygen uptake occurs both during hormone-induced and spontaneous maturation, but it seems to occur only after germinal vesicle breakdown (GVB).

In the present study we have investigated rabbit oocytes after an hCG injection to examine whether the increase in oxygen consumption also occurs in this species.

\section{Materials and Methods}

\section{Animals}

Ten albino virgin Swedish Land rabbits, 5-6 months old and weighing $2 \cdot 5-3 \mathrm{~kg}$, were used. They were housed in a controlled environment and given a standard pellet diet.

\section{Isolation of oocytes}

The animals were anaesthetized with pentobarbitone sodium (Nembutal: Abbott; $30 \mathrm{mg} / \mathrm{kg}$ ) injected via a marginal ear vein, and 100 i.u. hCG (Gonadex; Leo Ltd) was administered via the same route. The ovaries were removed through a laparotomy incision, one at a time, either before or at specific times after the hCG injection. After removal of the first ovary the animal was kept anaesthetized with the abdomen closed until the second ovary was removed. The ovaries were placed in buffer containing $300 \mathrm{i}$. u. hyaluronidase/ml (Type IV, Sigma), and oocyte-cumulus complexes were isolated by incising the largest follicles with a small knife. The cumulus cells were removed from the oocytes by repeated careful suction through glass capillaries with successively smaller diameter, the smallest being only slightly larger than that of the oocyte. After denudation the oocytes were washed twice in medium without hyaluronidase.

* Present address: Department of Obstetrics-Gynecology, and the Endocrine Laboratory, University of Miami. Florida, U.S.A. 


\section{Measurement of oxygen consumption}

Oxygen consumption was measured by a microspectrophotometric method using haemoglobin as an indicator of oxygen tension (Hultborn, 1974). After a single denuded oocyte was placed in haemoglobin-containing $(30-35 \mathrm{~mm})$ buffer in a small $(12.3 \mathrm{nl})$ gas-tight chamber, the shift in absorbance of monochromatic (435 nm) light in the buffer was recorded as oxygen tension decreased. Before the measurements, requiring approximately $15 \mathrm{~min}$ each, the oocytes were kept at room temperature $\left(22-23^{\circ} \mathrm{C}\right)$. All measurements were performed within $120 \mathrm{~min}$ after isolation of the ovary. The difference between the oxygen consumption of the first and the last oocyte from each ovary was not significant $(2 \pm 7 \%, n=14$ ovaries). Oxygen consumption is expressed as $\mathrm{nl} \mathrm{O}_{2} / \mathrm{h} /$ oocyte.

\section{Determination of maturational stage}

The germinal vesicle (GV), when present, was easily recognized under the dissecting microscope (Zeiss, $\times 40$ magnification). After respirometry all the oocytes without GV and most of those with GV were recovered, fixed with glacial acetic acid-ethanol $(1: 3 \mathrm{v} / \mathrm{v})$ and, after staining with aceto-orcein, the chromosomes were examined.

\section{Chemicals}

The medium used was a modified phosphate buffer, pH 7.4 (BMOC: Magnusson et al., 1977) containing 10 mM-L-glutamine (Bae \& Foote, 1975). Haemoglobin was prepared from outdated human blood (Hultborn, 1974).

\section{Statistics}

Values are presented as mean \pm s.e.m., $n=$ number of determinations (= number of oocytes) and statistical differences were calculated by analysis of variance followed by StudentNewman-Keul's multiple range test (Woolf, 1968).

\section{Results}

Nuclear maturation, in terms of germinal vesicle breakdown (GVB), occurred between 2 and $4 \mathrm{~h}$ after the hCG injection (Text-fig. 1). After $6 \mathrm{~h}$ most of the oocytes examined had reached metaphase I and by $8 \mathrm{~h} 56 \%$ were in anaphase I to metaphase II.

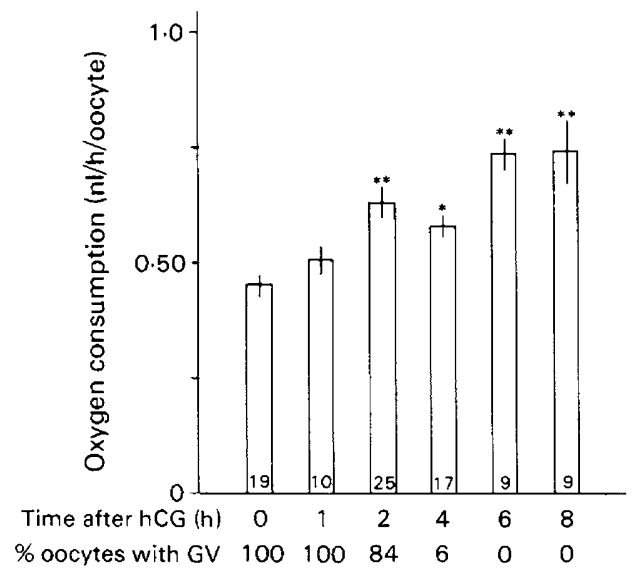

Text-fig. 1. Oxygen consumption by denuded rabbit oocytes isolated at various times after an i.v. injection of 100 i.u. hCG. Values are mean \pm s.e.m. for the no. of oocytes indicated within the bars. ${ }^{*} P<0.05,{ }^{* *} P<0.01$ compared with value at $0 \mathrm{~h} . \mathrm{GV}=$ germinal vesicle. 
Oxygen consumption increased with time after hCG and was already apparent by 2 h, i.e. before GVB occurs (Text-fig. 1). The drop at $4 \mathrm{~h}$ was not statistically significantly different from the value at $2 \mathrm{~h}$. Due to the experimental design, removing one ovary at a time, the animals were anaesthetized for various times before oophorectomy. To determine the possible effect of anaesthesia on the oxygen uptake by the oocyte the oocytes taken 0 or $2 \mathrm{~h}$ after hCG were isolated either from animals within $5 \mathrm{~min}$ from onset of anaesthesia or from animals anaethetized for $2 \mathrm{~h}$. In neither case was there any difference observed between the oxygen consumption of the oocytes that could be related to the length of anaesthesia.

\section{Discussion}

Although the number of oocytes examined in this study was rather small, the time-course of nuclear maturation after hCG injection correlated well with the time-course after coitus (Thibault, Gérard \& Ménézo, 1976) as far as resumption of meiosis and progress to metaphase I was concerned. This time-course of maturation was also similar to the findings in the rat in which the proportions of oocytes showing GVB 2 and $4 \mathrm{~h}$ after $\mathrm{LH}$ injection were 12 and $77 \%$ respectively (Magnusson et al., 1977) as compared to 16 and $94 \%$ in the present study 2 and $4 \mathrm{~h}$ after hCG. These findings also correlate well with the temporal relation between plasma $\mathrm{LH}$ levels and in-vivo resumption of meiosis in the adult pro-oestrous rat (Ayalon, Tsafriri, Lindner, Cordova \& Harell, 1972). The oxygen consumption of rat oocytes devoid of their cumulus cells increases after an LH injection (Magnusson et al., 1977). This increase became evident after 3-4 $\mathrm{h}$, when most of the oocytes had shown GVB. In fact, after $3 \mathrm{~h}$ oocytes with an intact GV had a lower oxygen consumption than oocytes with GVB. Also, oocytes maturing spontaneously in culture showed an increase in oxygen uptake parallel to nuclear maturation. With the present study we now confirm that denuded rabbit oocytes also increase oxygen consumption after injection of gonadotrophin. This increase was seen earlier than in the rat, and was significant by 2 $h$ after the hCG injection, when the germinal vesicle was still present.

In the present study the increase in oxygen uptake preceded the resumption of meiosis in contrast to the findings in the rat, but the role of this increase is not clear. It may represent evidence of increased energy metabolism in the oocyte. This is not surprising since the resumption of meiosis is associated with major changes in the oocyte, not only the nuclear maturation and extrusion of the first polar body, but also, for example, changes in the pattern and rate of protein synthesis (Warnes, Moor \& Johnson, 1977; Schultz, LaMarca \& Wassarman, 1978). Studies in the rat have, however, shown that nuclear maturation may occur even without any increase in oxygen consumption when oocytes are cultured without their surrounding cumulus cells (Magnusson, 1980) or in the presence of puromycin (Ekholm \& Magnusson, 1979). The rise in oxygen consumption is therefore probably not a prerequisite for nuclear maturation.

The present study has thus confirmed for the rabbit earlier findings for the rat that oocyte maturation is accompanied by an increase in oxygen consumption. The time relation between the maturation and the metabolic response is, however, different in the two species.

We thank Dr Kurt Ahrèn for valuable support; Dr R. Hultborn, for the stock solution of haemoglobin; and Mrs Britt-Marie Helder for typing the manuscript. The stay of W.J.L. as Visiting Scientist was made possible by a Fogarty Senior International Fellowship (TW 00318) and a Visiting Scientist Fellowship from the Swedish Medical Research Council (5732). The study was supported by grants from the Swedish Medical Research Council (27 and 5650), NIH (grant no. HD 08747 to W.J.L.), Magnus Bergvall's Foundation, T. A. A. Amundssons Fund, The Göteborg Medical Society and the Medical Faculty of Göteborg. 


\section{References}

Ayalon, D., Tsafriri, A., Lindner, H.R., Cordova, T. \& Harell, A. (1972) Serum gonadotrophin levels in pro-oestrous rats in relation to the resumption of meiosis by the oocytes. J. Reprod. Fert. 31, 51-58.

Bae, I.-H. \& Foote, R.H. (1975) Effects of hormones on the maturation of rabbit oocytes recovered from follicles of various sizes. J. Reprod. Fert. 42, $357-360$.

Ekholm, C. \& Magnusson, C. (1979) Rat oocyte maturation: Effects of protein synthesis inhibitors. Biol. Reprod. 21, 1287-1293.

Hultborn, R. (1974) A spectrophotometric method for analysis of oxygen consumption in vitro on the microscale. Acta physiol. scand., Suppl. 404, 1-47.

Magnusson, C. (1980) Role of cumulus cells for rat oocyte maturation and metabolism. Gamete Res. 3, $133-140$.

Magnusson, C., Hillensjö, T., Tsafriri, A., Hultborn, R.
\& Ahrén, K. (1977) Oxygen consumption of matur ing rat oocytes. Biol. Reprod. 17, 9-15.

Schultz, R.M., LaMarca, M.J. \& Wassarman, P.M. (1978) Absolute rates of protein synthesis during meiotic maturation of mammalian oocytes in vitro. Proc. natn. Acad. Sci. U.S.A. 75, 4160-4164.

Thibault, C., Gérard, M. \& Ménézo, Y. (1976) Nuclear and cytoplasmic aspects of mammalian oocyte maturation in vitro in relation to follicle size and fertilization. In Progress in Reproductive Biology, vol. 1, pp. 233-240. Ed. P. O. Hubinont. Karger, Basel.

Warnes, C.M., Moor, R.M. \& Johnson, M.H. (1977) Changes in protein synthesis during maturation of sheep oocytes in vivo and in vitro. J. Reprod. Fert. 49, 331-335.

Woolf, C.M. (1968) Principles of Biometry, 1st edn. D van Nostrand Co. Inc., Princeton. 